\title{
A VIDEOCONFERÊNCIA NO INTERROGATÓRIO DA PRISÃO EM FLAGRANTE
}

\author{
Nyeda Yuri Santos Kiyota Dan, Pablo Rodrigo França \\ Universidade do Oeste Paulista - UNOESTE, curso de Direito, Presidente Prudente, SP. E-mail: \\ nyedakiyota@hotmail.com
}

\section{RESUMO}

A prisão em flagrante no Brasil é instrumento excepcional de preservação e manutenção da ordem social, ao fazer cessar a consumação da atividade criminosa, com atribuição exclusiva da formalização dos atos ao Delegado de Polícia. Diante da morosidade e aumento de ações na persecução criminal de primeira fase, com preocupante escassez de servidores da segurança pública, no caso Autoridades Policiais, o presente estudo tem como objetivo discutir a possibilidade de aplicação da videoconferência nesta forma de prisão pré-cautelar. Ponderando quanto à proteção dos direitos fundamentais do capturado, haja vista ser o profissional responsável pela salvaguarda da legitimidade e adequação dos requisitos legais do ato com proteção aos direitos humanistas. Ao equiparar a medida tecnológica nesta espécie de prisão como a já realizada no processo criminal, a executoriedade se mostra concebível, não apenas sem o prejuízo aos direitos do acusado, notadamente em homenagem a economicidade de gastos e a celeridade procedimental.

Palavras chave: Prisão, Flagrante, Videoconferência, Delegado de Polícia.

\section{VIDEOCONFERENCE IN THE INTERROGATORY PRISON IN FLAGRANT}

\begin{abstract}
The arrest in flagrante in Brazil is an exceptional instrument of preservation and maintenance of the social order, when ceasing the consummation of the criminal activity, with exclusive attribution of the formalization of the acts to the Delegate of Police. Faced with the slowness and increase of actions in the first-stage criminal prosecution, with a worrying shortage of public security officials, in the case of Police Authorities, this study aims to discuss the possibility of applying videoconferencing in this form of pre-cautionary arrest, pondering The protection of the fundamental rights of the captured, should be the professional responsible for safeguarding the legitimacy and adequacy of the legal requirements of the act with protection of human rights. By equating the technological measure in this type of arrest like that already carried out in the criminal process, the enforceability is conceivable, not only without prejudice to the rights of the accused, notably in tribute to the cost-effectiveness and procedural speed.
\end{abstract}

Keywords: Prison, Flagrant, Videoconference, Police Officer.

\section{INTRODUÇÃO}

O Diário Oficial do Estado de São Paulo, em 12 de outubro de 2016, comentando sobre o colapso social da segurança pública trouxe dados estatísticos provenientes da Pasta da Secretaria de Segurança que são atemorizadores, ao constatar um déficit de $16 \%$ de vagas para Delegado de Polícia a serem preenchidas referido ano. Em virtude dessa exiguidade, um profissional fica responsável pela condução de mais de mil inquéritos e não raras vezes duas unidades ou equipes, o que de acordo com o presidente (à época) do Sindicato dos Delegados de Polícia de São Paulo 
(SINDPESP), tratava-se tarefa inexequível a coordenação de tal número de investigações, que acabava por ocasionar a não obtenção de um resultado efetivo.

Nesse contexto, embora o segmento seja de grande relevância a persecução penal de um país que não propicia uma eficaz segurança preventiva a coletividade, não há uma solução iminente para a crise que se arrasta ao longo do tempo, tendo em conta que o Poder Público não efetua novas contratações ou concursos suficientes.

Diante deste quadro, discutir e ponderar a viabilidade da aplicação da videoconferência no exclusivo ato da prisão em flagrante, presidido pelo Delegado de Polícia, parece ser inconteste, nada obstante o cuidadoso exame da legislação e impactos sociais.

Esse método tecnológico consiste na transmissão de sons e imagens em tempo real (AVENA, 2016, p.534). Ou seja, uma participação efetiva, mas, virtual.

No tocante a constitucionalidade da medida, mormente as garantias consubstancias na Carta Magna vigente, os princípios da presunção da inocência e dignidade da pessoa humana são contemplados no decorrer da utilização desta, não havendo divergência para com o inquérito policial executado de forma presencial.

Além, é vital sopesar que ao coferir tal medida estaria assegurada à preservação dos direitos fundamentais daquele que se encontra detido, haja vista o ordenamento jurídico pátrio ser norteado por um modelo garantista, proposto em um binômio embasado não simplesmente no direcionamento de uma pena, mas, essencialmente na proteção dos direitos e liberdades individuais.

O presente estudo tem por objetivo, refletir sobre a proficuidade da videoconferência como meio mitigatório que visa suprir à insuficiência presencial de autoridade policial, bem como proteção a garantia fundamental à segurança e ao andamento de uma atividade persecutória satisfativa que ampara a jurisdição. Isso, tendo em vista sua equiparação á àquela realizada no curso do processo criminal.

Neste enquadramento a discussão acadêmica de uma temática mostra-se imprescindível, uma vez apta a fomentar soluções no plano fático.

O objetivo desta pesquisa tenciona a expor conceitos, definições e as ferramentas necessárias, permitindo a assimilação do mecanismo, na percepção de que a adoção não promove prejuízo de direitos tidos como fundamentais, respaldando seu desenvolvimento e ampliando as preocupações da comunidade acadêmica das áreas jurídicas. Respalda-se em bibliografias, artigos eletrônicos, doutrinas, leis, dentre outros.

\section{METODOLOGIA}

A metodologia a ser aplicada na presente pesquisa diz respeito ao método hipotéticodedutivo, usando de forma auxiliar o comparativo, tendo em vista que se trata de investigação que irá abordar de forma breve o atual cenário da gestão aplicada pelos órgãos públicos da segurança no que tange ao ato da prisão em flagrante delito, com o objetivo de trazer maior segurança pública e jurídica, igualdade, ordem e coerência na aplicação do direito.

Da mesma forma será dada importância ao método científico como agente sistematizador, organizador e disciplinador na realização do trabalho intelectual, desenvolvido por meio de pesquisas bibliográficas, doutrinas, jurisprudências e artigos.

A pesquisa visa explorar realidades, descrever paradigmas e propor a coragem de programar soluções tecnológicas já existentes, que não esbarram no esmagamento de qualquer direito fundamental consagrado.

Destarte, para mais adequado desfecho do trabalho, essencial a pesquisa rápida sobre o direito penal e processual penal, na estrutura e fundamentos aplicados. 


\section{RESULTADOS}

O processo penal deve se adequar a contemporaneidade, buscando uma concreta prestação jurisdicional, atendendo ao princípio da celeridade fundido na Carta Magna (MOUGENOT, 2011). A repulsa ao uso de tecnologias atua em desfavor aos interessados, burocratizando a justiça. A implementação da videoconferência desempenha não só economia e agilização, como também atende a segurança da sociedade (BRASILEIRO, 2016).

Com a medida aplicada no ato das prisões em flagrante, duplicam-se as funções com o mesmo número de servidores, sem o risco pessoal das Autoridades Policiais que enfrentam cotidianamente estradas, em jornadas e escalas sem humanidade, com celeridade procedimental a partir do momento que não há necessidade de aguardar a chegada deste servidor garantidor, economicidade de gastos públicos e privados, na deambulação exigida, com a liberação mais breve dos agentes apresentantes da ocorrência e responsáveis pelo policiamento ostensivo para retorno a função precípua, bem como garantia de permanência mínima do capturado na unidade prisional detentora.

A ordem e pacificação social não sofrem baixas, nem mesmo nos direitos individuais que são mantidos pelos demais servidores de carreira, bem como os exames cautelares requisitados ao Instituto Médico Legal em cada detenção, como exigência natural e de rotina profissional.

Assim, a sociedade deve evoluir em convergência as suas necessidades, com o conhecimento e tecnologia disposta, em benefício amplo e coletivo, alterando rotinas arraigadas há décadas e que contemporaneamente não são mais condizentes.

\section{DISCUSSÃO}

O inquérito policial realizado pela polícia judiciária é sem dúvidas a ferramenta mais eficiente e legítima de investigação realizada pelo Estado, basta à verificação simplória da superlotação carcerária que, em quase a sua totalidade, é desenvolvida pautada neste procedimento de primeira fase.

Das espécies de prisões, segundo a doutrina e em síntese apertada, pode ser dividida em: 'prisão pena' (decorrente de uma condenação transitada em julgado), assim como 'sem pena' (decretada mesmo antes de qualquer decisão final). Destas, ainda, são subdivididas em civil, administrativa, disciplinar e processual ou cautelar. Em face da temática escolhida manteremos no texto apenas a abordagem da última.

A prisão em flagrante é colocada por alguns como subespécie da prisão processual ou, para outros, como fase pré-cautelar ou subcautelar da prisão preventiva, em face das recentes alterações no vigente Código de Processo Penal incluídas pela Lei 12.403/2011 (MOUGENOT, 2013).

De toda sorte, o termo flagrante advém do latim flagrare, tem sentido de queimar, arder (MIRABETE, 1997). A doutrina comumente conceitua como momento de certeza visual do crime, que acarreta a prisão do indivíduo surpreendido. Continua Julio Fabbrini Mirabete (1997, p.370):

Em sentido jurídico, flagrante é uma qualidade do delito, é o delito que está sendo cometido, praticado, é o ilícito patente, irrecusável, insofismável, que permite a prisão do seu autor, sem mandado, por ser considerado a 'certeza visual do crime'. Assim, a possibilidade de se prender alguém em flagrante de delito é um sistema de autodefesa da sociedade, derivada da necessidade social de fazer cessar a prática criminosa e a perturbação da ordem, tendo também o sentido de salutar providência acautelatória da prova da materialidade do fato e da respectiva autoria. 
A Constituição Federal de 1988 traz a base da legalidade dessa espécie de prisão, em seu artigo 5으, inciso LXI, "ninguém será preso senão em flagrante de delito ou por ordem escrita e fundamentada de autoridade judiciária competente, salvo nos casos de transgressão militar ou crime propriamente militar definido em lei". Abarcando o preceito de que prisão é exceção à regra, que é a liberdade, o rol acima elencado é numerus clausus no tocante as hipóteses de cárcere.

Assim, para que seja legítima a prisão em flagrante é imprescindível o preenchimento de requisitos predefinidos em lei, sob pena de imediato relaxamento por ilegalidade. O Código de Processo Penal, artigo 304, apresenta algumas das imposições (grifo nosso):

Apresentado o preso à autoridade competente, ouvirá esta o condutor e colherá, desde logo, sua assinatura, entregando a este cópia do termo e recibo de entrega ao preso. Em seguida, procederá à oitiva das testemunhas que o acompanharem e ao interrogatório do acusado sobre a imputação que lhe é feita, colhendo, após cada oitiva suas respectivas assinaturas, lavrando, a autoridade, afinal, o auto.

A referida autoridade competente apta a efetuar o interrogatório do capturado e lavratura do auto de prisão, bem como a composição do flagrante em fases, ou seja, os acontecimentos subsequentes ao ato de prisão em si: captura, condução coercitiva, lavratura do auto de prisão e recolhimento á prisão, é o precitado Delegado de Polícia. Entre todos os atos, especialmente e de maneira personalíssima, a autoridade policial executa o interrogatório, que tem finalidade de verificar se a captura tem sustentação legal exigida pelo artigo 302 do mesmo estatuto repressivo.

Diante do exposto, destaca-se que a participação da autoridade policial é de crucial relevância à fórmula garantista escolhida pela legislação, em razão de ser o primeiro guardião do preso, da lei, da justiça, responsável direto em exaltar todos os direitos fundamentais. Nada obstante, em momento algum a lei exige a presença física do servidor suprarreferido, apenas "apresentação à autoridade competente", logo, compete ao intérprete, a depender da exegese adotada, a adequação a realidade, inclusive, aderindo naturalmente à tecnologia disponível que, de certo, continua mantendo a ativa participação deste servidor que, por inúmeros fatores já elencados, continuaria sua função de maneira próxima, contudo, virtual.

Já dissemos que o déficit de servidores na polícia judiciária, entre outros fatores, é uma realidade que obstrui o desenvolvimento adequado da atividade investigatória que, para amenizar custos e a realidade encontrada, já motivou dezenas de projetos, hoje modelos de gestões, que culminaram no fechamento de delegacias ou setores especializados, mesmo que em períodos ou dias, na inclusão de adicionais por acumulação de unidades, ou, gratificação pelo trabalho no horário que seria do descanso. E a crise anunciada tem importado em uma reação em cadeia deplorável à proficiência da justiça.

Isto posto e diante dos vários fundamentos, a utilização da videoconferência na prisão em flagrante figura meio de mitigação as imperfeições desencadeadas pelo Estado, tal negligência não é meramente defeito ao sistema que tem como intuito salvaguardar a coletividade, mas recalcitrar reiteradamente os direitos fundamentais (SANNINI NETO, 2016).

A adoção do procedimento constata proveitos indubitáveis, como parcimônia dos referidos servidores públicos, por conseguinte um único Delegado de Polícia seria capaz de atender a todos os flagrantes da localidade pela qual é o responsável. 0 artigo 308 do Código de Processo Penal retrata um cenário em que outra falha estrutural é sanada pelo emprego da medida: "Não havendo autoridade no lugar em que se tiver efetuado a prisão, o preso será logo apresentado à do lugar mais próximo".

A definição de videoconferência foi defendida por Maria Lúcia Fernandes Carneiro (2007): 
Entende-se que videoconferência é uma tecnologia que possibilita a comunicação em tempo real entre grupos de pessoas ou mesmo de pessoa para pessoa em locais distintos, com transmissão de áudio e vídeo simultaneamente, utilizando-se de câmeras de vídeo, microfones, monitores de vídeo e caixas de som.

E não há como já asseverado resquício de constrangimentos aos direitos fundamentais garantidos, ao contrário, trata-se de efetivá-los sem tardança. A discussão impera no tocante a preservação dos direitos fundamentais do preso, todos regulados pela Constituição Federal.

Aliás, a constitucionalidade da medida minimamente deve ser equiparada ao determinado pela Lei no 11.900 e 08 de janeiro de 2009, que permite aos magistrados realizarem interrogatório de réus e testemunhas através da videoconferência. Se no interrogatório realizado no processo, persecução de segunda fase, onde o contraditório deve ser pleno e a ampla defesa exaltada, a moderna medida é realizada quiçá na persecução de primeira fase, com todos os atos e órgãos controladores da polícia judiciária.

\section{CONCLUSÃO}

"O moderno processo penal deve ser contemporâneo. A busca pela célere e efetiva prestação jurisdicional encontra-se consubstanciada na Constituição Federal” (MOUGENOT, 2011, p. 395).

Se ao magistrado que produz o seu juízo de valor com base em todos os princípios e fundamentos constitucionais, bem como nos fatos inerentes a infração penal e pessoa do acusado, buscando estar o mais próximo possível à verdade real, lhe é concedido o uso da videoconferência, deve-se o mesmo aplicar com mais razão ao Delegado, haja vista, ter o flagrante natureza administrativa, ao dispensar ordem judicial conferindo somente detenção do suposto agente e não tendo condão de contaminar eventual instauração de processo crime, restando unicamente a autoridade judiciária manifestar-se acerca do relaxamento ou não da prisão, sem a imprescindível consagração da ampla defesa e contraditório.

No mesmo passo, entendimento de Renato Brasileiro (2016, p. 919):

A nosso juízo, a realização do interrogatório por videoconferência não atende somente aos objetivos de agilização, economia e desburocratização da justiça. Atende também à segurança da sociedade, do magistrado, do membro do Ministério Público, dos defensores, dos presos, das testemunhas e das vítimas, razão pela qual não pode ser tachada de inconstitucional.

Outros princípios garantidores previstos na Constituição Federal tanto para a o inquérito como para o processo criminal, acautelam e demonstram a prestabilidade da providência. Seja o principio da eficiência, estabelecido no artigo 37 caput, ou mesmo da presunção de inocência, ambos são ratificados na medida, pois, não dispensam o cumprimento dos ditames expressos na legislação.

É ostensível que a prisão em flagrante atua com feitio protetivo da Constituição, sua natureza de reprimir, em verdade, previne infrações penais, pois, dissemina na coletividade sentimento de que não há impunidades aos agentes infratores, bem como desencoraja a prática de atos que atentem aos dispositivos normativos.

A aversão ao uso de tecnologias à aplicabilidade da lei só a torna morosa e de alto custo aos interessados, que arcam com inúmeros impostos e tributos, e ao final não vislumbram a justiça almejada. 


\section{REFERÊNCIAS}

AVENA, Norberto Cláudio Pâncaro. Processo Penal. 9ạ Ed. São Paulo: Método, 2016.

MOUGENOT BONFIM, Edilson. Curso de Processo Penal. 6a Ed. São Paulo: Saraiva, 2011. . Curso de Processo Penal. 8a Ed. São Paulo: Saraiva, 2013.

BRASIL. Constituição (1988). Constituição da República Federativa do Brasil: promulgada em 5 de outubro de $1988 . \quad$ Disponível em <http://www.planalto.gov.br/ccivil_03/Constituicao/Constituicao.htm>. Acesso em 27 jul.2017.

BRASIL. Decreto-Lei no 3.689, de 3 de outubro de 1941. Disponível em http://www.planalto.gov.br/ccivil_03/decreto-lei/Del3689.htm. Acesso em 01 ago.2017.

BRASIL. Lei no 11.900, de 8 de janeiro de 2009. Disponível em <http://www.planalto.gov.br/ccivil_03/_Ato2007-2010/2009/Lei/L11900.htm>. Acesso em 4 jul.2017.

BRASIL. Lei o 12.403, de 4 de maio de 2011. Disponível em <http://www.planalto.gov.br/ccivil_03/_ato2011-2014/2011/lei/12403.htm>. Acesso em 25 jul.2017.

CARNEIRO, Maria Lúcia Fernandes. VIDEOCONFERÊNCIA: Ambiente para educação á distância. Disponível em: <http://penta.ufrgs.br/pgie/workshop/mara.htm>. Acesso em: 21 mar. 2017.

BRASILEIRO LIMA, Renato. Manual de Processo Penal. 4a Ed. Salvador: Juspodivm, 2016.

MIRABETE, Júlio Fabbrini. Processo Penal. 7 ed. São Paulo: Atlas, 1997. . Processo Penal. 10 ed. São Paulo: Atlas, 2000.

SANNINI, Francisco Neto. Prisão em flagrante por videoconferência. Disponível em: <https://canalcienciascriminais.com.br/prisao-flagrante-videoconferencia/>. Acesso em: 21 mar. 2017.

SÃO PAULO. Diário Oficial Poder Legislativo, 12 de outubro de 2016. Disponível em: <https://www.imprensaoficial.com.br/DO/BuscaDO2001Documento_11_4.aspx?link=/2016/legisl ativo/outubro/12/pag_0017_6HQ07G83C5E5Ge1CGO28K2G1OV1.pdf\&pagina=17\&data=12/10/2 016\&caderno=Legislativo\&paginaordenacao=100017>. Acesso em: 21 mar. 2017. 